\title{
Maternal and child health interventions in Nigeria: a systematic review of published studies from 1990 to 2014
}

Musa Abubakar Kana ${ }^{1,2^{*}}$, Henry Victor Doctor ${ }^{3+}$, Bárbara Peleteiro ${ }^{2,4 \dagger}$, Nuno Lunet ${ }^{2,4 \dagger}$ and Henrique Barros ${ }^{2,4+}$

\begin{abstract}
Background: Poor maternal and child health indicators have been reported in Nigeria since the 1990s. Many interventions have been instituted to reverse the trend and ensure that Nigeria is on track to achieve the Millennium Development Goals. This systematic review aims at describing and indirectly measuring the effect of the Maternal, Newborn, and Child Health (MNCH) interventions implemented in Nigeria from 1990 to 2014.

Methods: PubMed and ISI Web of Knowledge were searched from 1990 to April 2014 whereas POPLINE ${ }^{\circledR}$ was searched until 16 February 2015 to identify reports of interventions targeting Maternal, Newborn, and Child Health in Nigeria. Narrative and graphical synthesis was done by integrating the results of extracted studies with trends of maternal mortality ratio (MMR) and under five mortality (U5MR) derived from a joint point regression analysis using Nigeria Demographic and Health Survey data (1990-2013). This was supplemented by document analysis of policies, guidelines and strategies of the Federal Ministry of Health developed for Nigeria during the same period.

Results: We identified 66 eligible studies from 2,662 studies. Three interventions were deployed nationwide and the remainder at the regional level. Multiple study designs were employed in the enrolled studies: pre- and post-intervention or quasi-experimental $(n=40 ; 61 \%)$; clinical trials $(n=6 ; 9 \%)$; cohort study or longitudinal evaluation ( $n=3 ; 5 \%)$; process/output/outcome evaluation $(n=17 ; 26 \%)$. The national MMR shows a consistent reduction (Annual Percentage Change (APC) $=-3.10 \%, 95 \% \mathrm{Cl}:-5.20$ to $-1.00 \%$ ) with marked decrease in the slope observed in the period with a cluster of published studies (2004-2014). Fifteen intervention studies specifically targeting under-five children were published during the 24 years of observation. A statistically insignificant downward trend in the U5MR was observed (APC $=-1.25 \%, 95 \% \mathrm{Cl}:-4.70$ to $2.40 \%$ ) coinciding with publication of most of the studies and development of MNCH policies.
\end{abstract}

Conclusions: The development of MNCH policies, implementation and publication of interventions corresponds with the downward trend of maternal and child mortality in Nigeria. This systematic review has also shown that more $\mathrm{MNCH}$ intervention research and publications of findings is required to generate local and relevant evidence.

Keywords: Maternal and child health, Interventions, Coverage, Effectiveness, Systematic review, Nigeria

\footnotetext{
* Correspondence: musakana77@yahoo.com

${ }^{\dagger}$ Equal contributors

'Department of Community Medicine, Faculty of Medicine, Kaduna State

University, Kaduna, Nigeria

2EPIUnit - Instituto de Saúde Pública da Universidade do Porto (ISPUP),

Porto, Portugal

Full list of author information is available at the end of the article
}

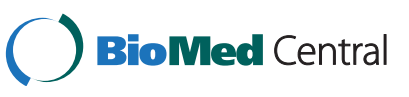

(c) 2015 Kana et al.; licensee BioMed Central. This is an Open Access article distributed under the terms of the Creative Commons Attribution License (http://creativecommons.org/licenses/by/4.0), which permits unrestricted use, distribution, and reproduction in any medium, provided the original work is properly credited. The Creative Commons Public Domain Dedication waiver (http://creativecommons.org/publicdomain/zero/1.0/) applies to the data made available in this article unless otherwise stated. 


\section{Background}

Poor maternal and child health indicators have been a recurring public health challenge in Nigeria since documentation of national Maternal, Newborn, and Child Health (MNCH) statistics began in the early 1990s [1-15]. To address this problem, many interventions were instituted to ensure that Nigeria achieves the relevant Millennium Development Goals (MDGs) [11,16-25]. Nevertheless, various intervention reports have documented mixed findings of the successes and challenges as well as threats to the attainment of MDGs 4 and 5 (child and maternal mortality reduction, respectively) in Nigeria [10,21,22,26-32]. It has been observed that Nigeria is off track in meeting MDG 4 and according to the United Nations mortality estimates, Nigeria has only achieved an average of $1.2 \%$ annual reduction in under-five mortality since 1990. And in order to meet MDG 4, Nigeria needed to have achieved an annual reduction rate of $10 \%$ in the five years leading to 2015 [10-33].

To design $\mathrm{MNCH}$ interventions for post-2015 Nigeria, it will be imperative to provide evidence-based assessment of the previously implemented interventions in terms of volume, coverage, and effectiveness. This will respond to calls for evidence-based decision making and the recognition that better-informed decisions enhance impact and cost-effectiveness [34-38]. Consequently, the application of systematic reviews is essential in strengthening the capacity of institutions to make evidence-based decisions due to its transparent, rigorous, replicable, and timely assessments [35-40].

The primary objective of this systematic review is to identify and synthesize published studies on $\mathrm{MNCH}$ interventions in Nigeria from 1990 to 2014. We specifically made a cross-sectional description (trend in time and place) of the interventions with respect to study design and type of intervention as well as target population, coverage and outcome of interventions. The secondary objective was to examine concurrent trends in the development of $\mathrm{MNCH}$ policies and publication of intervention studies with maternal, newborn, and under-five mortality using published data to represent rates at different times between 1990 and 2014 .

\section{Methods}

\section{Search strategy}

PubMed $^{\oplus}$, ISI Web of Knowledge ${ }^{\mathrm{TM}}$ and POPLINE ${ }^{\ominus}$ were searched for articles published from 1 January 1990 to 17 April 2014 (16 February 2015 for POPLINE ${ }^{\circledR}$ ) to identify studies reporting interventions targeting women of childbearing age and children in Nigeria from 1990 to 2014. The year 1990 was selected as the starting point because the availability of national level estimates of $\mathrm{MNCH}$ indicators started with the 1990 Demographic and Health Survey (DHS) $[12,13,15,41,42]$. The search expression included synonyms and $\mathrm{MeSH}$ terms, which were as follows: (maternal OR child OR newborn) health (Nigeria OR Nigerian) (strategies OR promotion OR intervention OR program OR programme OR rural). An additional step involved the supplemented searches of reference lists of the included articles to assess whether more eligible studies could be identified and included. The search and study selection process is provided in the systematic review flow chart (See Figure 1) and PRISMA checklist (Additional file 1).

\section{Study inclusion and exclusion criteria}

A list of references of published studies was generated and independently screened by two reviewers (MK and HD) in three consecutive steps, by applying pre-defined criteria. First, studies were excluded considering only information presented in the title and abstract. Second, full texts of articles not previously excluded were assessed to determine their eligibility for the review. And finally, full texts were re-evaluated for data extraction.

The search strategy and selection criteria were based on the guidelines for systematic reviews of health promotion and public health interventions [40]. The criteria used to select studies primarily reflected the questions being answered in this review [40,43]. The criteria for exclusion of studies were applied step wise (criterion 1 to 5) on each study and a study was excluded if it did not satisfy the first or a subsequent criterion: (1) Type of Study: the noneligible studies were review articles (except systematic review of interventions), editorial, comment, guidelines and cross-sectional studies; (2) Intervention: studies that were non-interventional were ineligible; (3) Topic of study: studies with topics not reporting on $\mathrm{MNCH}$ were excluded; (4) Target population: studies that were not targeting mothers or under-five children in Nigeria were not included; and (5) Outcome: studies that were not reporting on $\mathrm{MNCH}$ outcome indicators were disqualified. International studies that included Nigeria were covered by the review.

\section{Data extraction strategy}

Disagreements between the independent assessments of the reviewers (MK and HD) were resolved by consensus or after discussion with a third researcher (BP). Two investigators (MK and $H D$ ) evaluated independently the selected studies to extract the data on sampling procedures; sample characteristics; rationale of study; type of intervention; sponsorship of intervention; outcome of intervention in terms of maternal health promotion; prevention of obstetric complications; intermediate outcome targeting interventions - contraceptives; child health promotion; prevention and treatment of childhood diseases; and health system strengthening. Differences in the data extracted by the two investigators were discussed until 


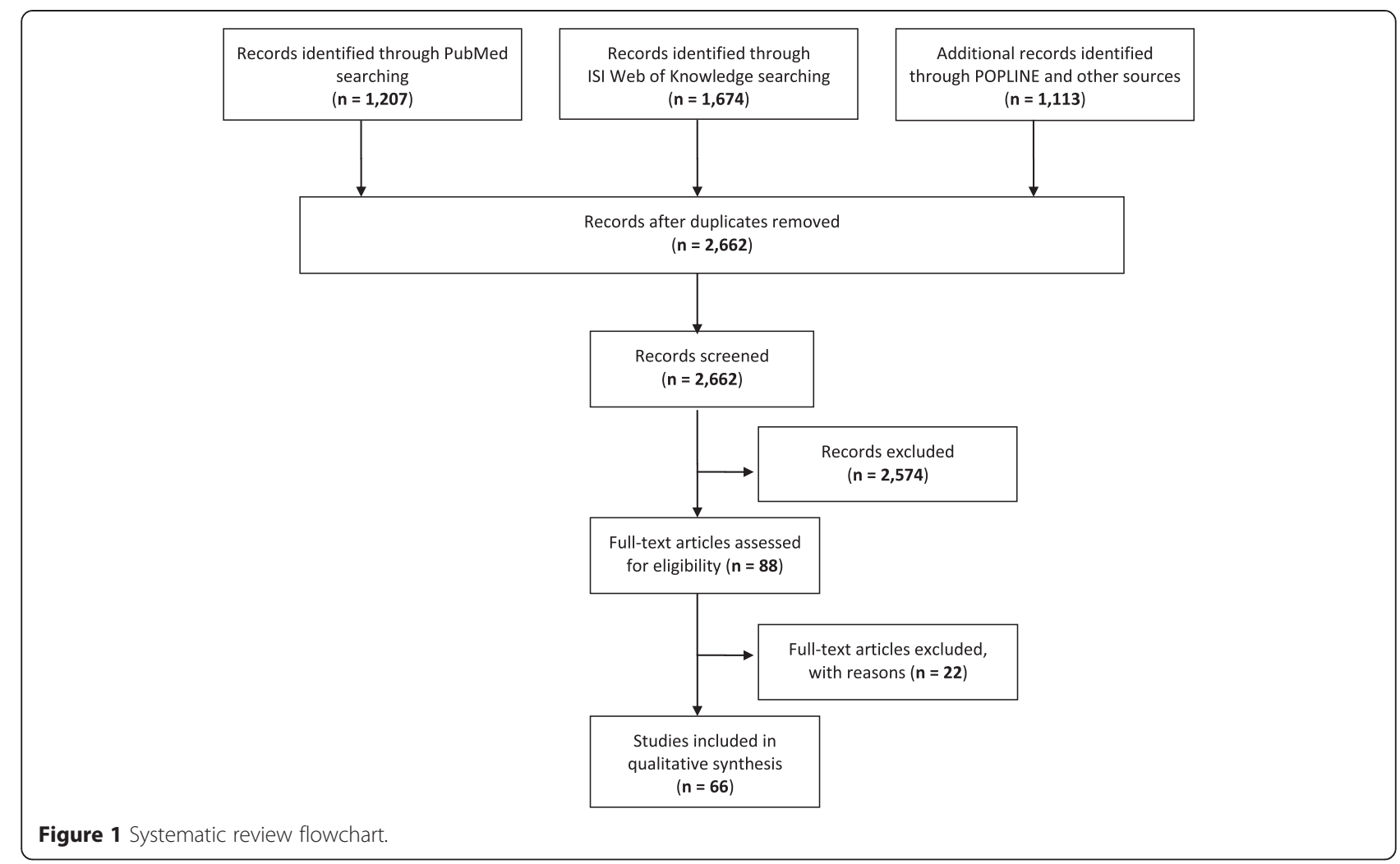

consensus, and involving a third researcher (BP), whenever necessary.

\section{Data synthesis and presentation}

A narrative and graphical synthesis was used to analyze and present findings. The results of data abstraction were summarized in Additional file 2: Table S1, which outlines the type, objective and target of intervention, coverage and measurement of effect for each intervention. We summarize and present the qualitative synthesis of the characteristics of the studies (See Additional file 2: Table S1 for data extraction tool). The result of the systematic review was also integrated into the charts outlining the trend of maternal and under-five mortality. The classification of interventions adopted was according to the level of health care delivery. And there are some interventions that are targeting multiple levels of care because interventions and strategies for improving $\mathrm{MNCH}$ are closely related and provided through a continuum of care approach [44]. The findings were also mapped to illustrate the geographical distribution of published studies based on cumulative number of interventions implemented per state using ArcGIS [45].

\section{Maternal and under-five mortality trends}

To monitor trends in maternal and under-five mortality, we derived data from the Nigeria Demographic and
Health Surveys (DHS) from 1990 to 2013 [12-42]. Poisson regression analysis was performed using the Joinpoint software $[46,47]$, in order to identify significant changes in the mortality trends (allowing for up to 1 joinpoint). For each of the segments obtained in the best model, the estimated annual percent change (APC) was computed by fitting a regression line to the natural logarithm of the rates using calendar year as a regressor variable (i.e., given $\mathrm{y}=\mathrm{a}+\mathrm{b} x$ where $\mathrm{y}=\ln$ (rate) and $x=$ calendar year, the APC is estimated as $100 \times(\mathrm{eb}-1))$.

\section{Document analysis of national policies, strategies, and guidelines for $\mathrm{MNCH}$}

The review of national $\mathrm{MNCH}$ policies, strategies, and guidelines was conducted by document analysis of an annotated national bibliography on digitized health policies and guidelines of the Federal Ministry of Health from 1988-2012 [48]. Policies published between 2012 and 2014 were derived by supplementary search. Since policies normally take long to be developed and enacted, additional literature about $\mathrm{MNCH}$ policies or healthassociated laws (e.g. National Health Act 2014) enacted between 1990 and 2014 were sought from publications of relevant Government institutions available as printed documents and on the Internet, including information websites. 


\section{Results}

Review of the published $\mathrm{MNCH}$ interventional studies in Nigeria (1990-2014)

Sixty-six eligible studies were identified from 2,662 studies, after applying pre-defined exclusion criteria to the title/ abstract and the full text evaluation [18,20,22,31,49-108]. Additional file 2: Table S1 presents a detailed description of the included studies. The thematic qualitative synthesis of the publications presented below examines the authorship, intervention-publication interval, geographical location, target population, intervention strategy, coverage and their outcomes. Some of the studies did not provide information on one or more of the above themes thus limiting the total number of studies being reported on some thematic features.

\section{Author reference, publication year, geographical location and setting of intervention}

Nigerian nationals as first authors accounted for 52 (79\%) of studies and the remainder 14 (21\%) had nonNigerian nationals as first authors. Among the studies included in this review, 52 (79\%) were published in international scientific publications, 7 (10.5\%) in Nigerianbased journals and 7 (10.5\%) were evaluation reports. The frequency of publications between 1990 and 1999 was 8 (12\%), in the decade of 2000-2009 was 21 (32\%) while the majority 37 (56\%) of the included studies were published between 2010 and 2014. The average number of publications per year in the 24 years of observation was 2.75 papers per year. The interval between the completion of intervention and publication ranged from $0-8$ years with a mean of $2.57 \pm 1$ years. There were studies reporting on interventions in a single region 50 (78\%), multiple regions $11(17 \%)$ or national coverage $3(5 \%)$. The distribution of implemented intervention studies within Nigeria according to geo-political regions: north-west (10), north-central (3), north-east (3), south-east (12), south-south (6) and south-west (16). There was one study reporting on multiple international sites including Nigeria. Further analysis showed that $20(33.3 \%)$ of these studies were conducted in urban, $32(53.3 \%)$ in rural or eight $(13.3 \%)$ in both settings. The site of intervention was classified as heath system $(n=5)$ community based $(n=42)$ and hospital based $(n=19)$, which could be first or referral level.

\section{Implementing organizations, sponsorship, year and duration of implementation}

The sponsorship/implementation of the interventions were by Government of Nigeria $(n=9)$, foreign donors/ implementing partners $(\mathrm{n}=15)$ or academic/health institutions $(n=25)$. Joint sponsorship or implementation partnerships were reported in 15 (22.7\%) intervention studies. The Government of Nigeria included its three tiers (federal, state or local) and their resources (financial, human and material) were used to facilitate the implementation of $\mathrm{MNCH}$ interventions. The distribution of the duration of implementation were as follows: less than a year $(n=31), 1-2$ years $(n=7), 3-5$ years $(n=13), 5-9$ years $(n=2), 10$ years or more $(n=2)$. The duration of implementation ranged from 1 month to 120 months (10 years) with a mean of 25.1 months (2.1 years).

\section{Target population, selection criteria and sample size}

Women of childbearing age were targeted in 37 (56\%) of the included studies, under-five children were the focus in 18 (27\%) interventions and both were targeted in $11(17 \%)$ interventions. The guidance for the selection of intervention area was specified by epidemiological factors (e.g. high burden of $\mathrm{MNCH}$ problems) in $31(48 \%)$ studies or purposively in $34(52 \%)$. The sample sizes were small population studies of $<100$ participants ( $n=12$; or $20 \%$ ), medium scale of $100-1000$ participants $(\mathrm{n}=30 ; 49 \%)$ and large population studies of more than 1000 participants $(n=19 ; 31 \%)$.

\section{Study design, intervention strategies and outcomes}

Multiple study designs were employed in the enrolled studies; pre/post-intervention/quasi-experimental ( $\mathrm{n}=40$; $61 \%)$, clinical trials (randomized or non-randomized) $(\mathrm{n}=$ 6; 9\%), cohort study or longitudinal evaluation $(n=3 ; 5 \%)$, process/output/outcome evaluation ( $n=17 ; 26 \%$ ). Only 23 (35\%) of studies had a control or comparison group, while $43(65 \%)$ did not. The range of interventions were targeting adolescents and pre-pregnancy $(\mathrm{n}=12 ; 18 \%)$, pregnancy ( $\mathrm{n}=9 ; 14 \%)$, childbirth $(\mathrm{n}=12 ; 18 \%)$, postnatal (mother and newborn) $(\mathrm{n}=1 ; 2 \%)$, infancy and childhood (19; 29\%), integrated maternal, newborn, and child health (crosscutting community and health system strategies) $(\mathrm{n}=$ 13; 19\%). The outcomes of the different interventions included maternal health promotion (e.g. utilization of family planning, antenatal care, and prevention of mother to child transmission of HIV) $(\mathrm{n}=12 ; 18 \%)$, prevention and management of obstetric complications (e.g. safe management of eclampsia, ante and postpartum heamorrhage, and clinical audit of quality of obstetrics services) ( $n=20 ; 30 \%$ ), child health promotion (e.g. immunization and infant feeding) $(\mathrm{n}=5 ; 8 \%)$; prevention and treatment of childhood diseases (e.g. Insecticide treated net (ITN) use and home management of malaria) $(n=16 ; 24 \%)$, and health system strengthening (e.g. policy for free $\mathrm{MNCH}$ services and electronic health information management system) ( $\mathrm{n}=13 ; 20 \%)$.

\section{Narrative and graphical synthesis}

The multiplicity of intervention designs, strategies and outcomes made quantitative methods, including metaanalysis and effect size for synthesis impossible and inappropriate. Therefore, the published intervention studies 
were categorized and described for the coverage and indirect measurement of effectiveness as reported in the following narrative and graphical synthesis.

Trends in maternal mortality in Nigeria, 1990-2013

Figure 2 illustrates the trend of maternal deaths. The national maternal mortality ratio (deaths per 100,000 live births) shows a consistent reduction during the period of observation ( $\mathrm{APC}=-3.10 \%, 95 \% \mathrm{CI}:-5.20$ to $-1.00 \%)$ and a marked decrease in the slope is observed in the period that features a cluster of published studies (2004-2014).

\section{National trend of under-five mortality rate in Nigeria, 1990-2013}

Although not statistically significant, a downward trend in the under-five mortality is observed ( $\mathrm{APC}=-1.25 \%$, 95\% CI: -4.70 to $2.40 \%$ ) and coincides with the implementation of most of the studies (Figure 3) during the first decade of the 21st century.

\section{Regional trend of under-five mortality rate in Nigeria, 1990-2013}

Despite the decline observed in almost all regions during the period of 1990-2014, regional variation in the rate of decline of under-five mortality rate (U5MR) was observed (Figure 4). North-central region shows a slight increase from 1999 to 2013 (APC $=0.43 \%, 95 \%$ CI: -13.60 to $16.70 \%)$, while the highest decline was observed in the South-south region during 2003-2013 (APC $=-6.38 \%$, 95\% CI: -17.60 to $6.30 \%)$. The regions with consistently the highest U5MRs are the north-west and the north-east.

\section{Geographical coverage of published MNCH interventions in Nigeria, 1990 to 2014}

The geographical distribution of the cumulative number of interventional studies per state in the six geo-political regions of Nigeria is displayed in Figure 5. South-western Nigeria is the geo-political region with the highest coverage (25) of published interventional studies. The north-eastern and the north-central sub-regions recorded 14 and 10 studies each whereas in the north-west, south-east and south-south the frequency of published studies for the period of observation was 23, 15 and 10 studies, respectively. Only three studies had national coverage whereas others were targeting two regions (6), three regions (3) and four regions (2).

\section{Characteristics and developmental trend of national policies, strategies and guidelines for $\mathrm{MNCH}$}

Thirty-thirty policies and guidelines for $\mathrm{MNCH}$ were introduced in Nigeria since the development of the National Health Policy in 1988 with a revision done in 2005 (Figure 6). Although the intervening period (19901999) had little development, there has been a steady increase in the number of policies and revisions since 2000. The relationship between the intervention studies and development of policies is mixed. A clear example of evidence derived from local intervention studies preceding policy or guideline is the training manual on the use of Magnesium Sulphate (2010). There was multi-centric intervention studies conducted between 2006-2008 [60,62], which produced favourable results about the effectiveness of Magnesium Sulphate in the management of pre-eclampsia. On the other hand there are interventions [22], which were executed after the development of the integrated maternal, newborn and child health strategy (IMNCH; 2007). On

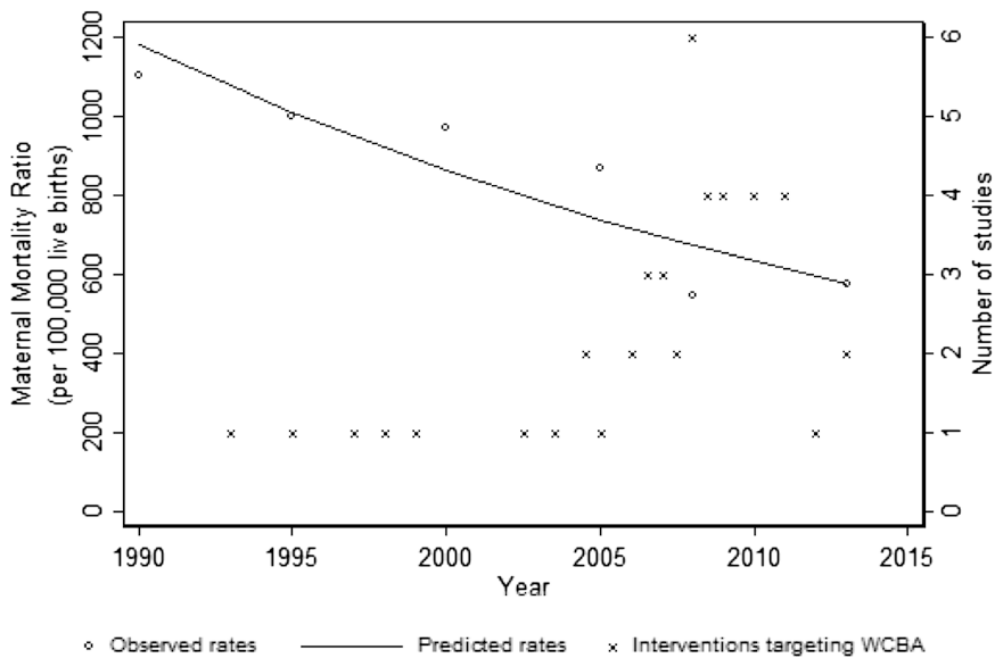

Figure 2 Line graph illustrating the trends in maternal mortality ratio and distribution of maternal health intervention studies in Nigeria, $1990-2013$. 


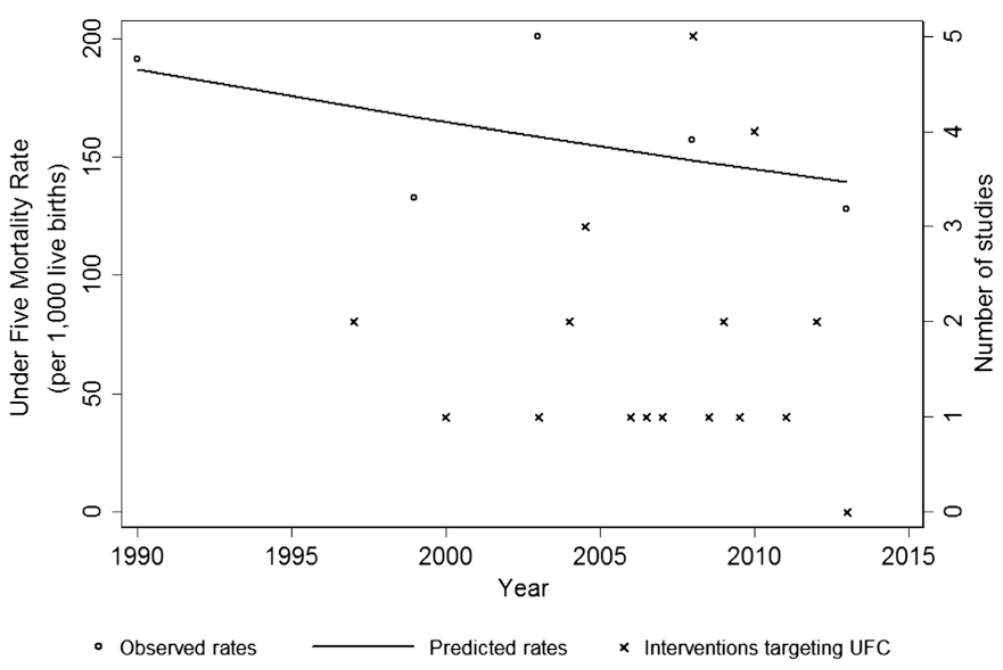

Figure 3 Line graph illustrating the trends of under-five mortality rate and distribution of child health intervention studies in Nigeria, 1990-2013.

the whole many of the policies have no temporal association with the intervention studies.

\section{Discussion}

This systematic review presents a cross-sectional description and an indirect measurement of the coverage and effectiveness of the published $\mathrm{MNCH}$ interventions implemented in Nigeria since 1990. During the 24 years of observation, the Government of Nigeria, academic/health institutions, and development partners have jointly implemented and published a number of intervention projects to promote $\mathrm{MNCH}[18,20,22,30,31,49-108]$. Results from this systematic review showed that majority $(90 \%)$ of the interventions were commenced after 2000 and 65\% were published between 2010 and 2014. This development may have been influenced by the increased awareness and commitment by the national Government and health authorities after the Millennium Declaration [109]. Our findings show that since 2000 there has been a simultaneous improvement in the development of $\mathrm{MNCH}$ policies, guidelines and strategies with that of intervention implementation and publication. Another explanation is the coincidence in the progressive increase of foreign aid and technical support to Nigeria since 1999 when there was restoration of democratic governance [110].

\section{Measurement of coverage and effectiveness of interventions}

In this study, we found that the national MMR has consistently reduced during the period of observation (1990-

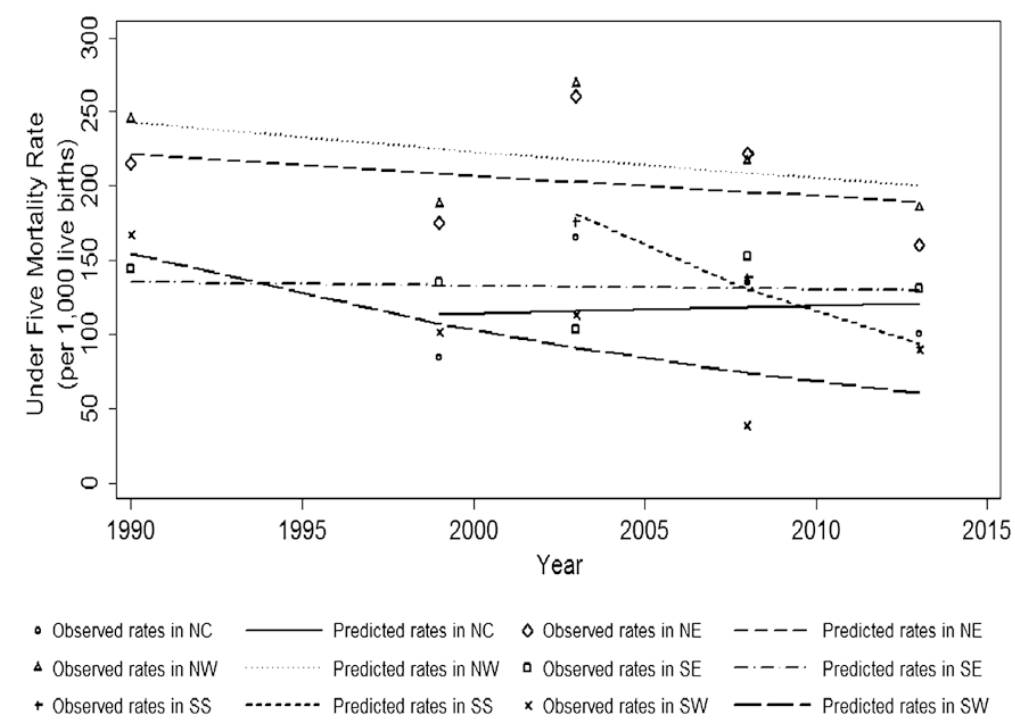

Figure 4 Line graph illustrating the regional trends of under-five mortality rate in Nigeria, 1990-2013. 


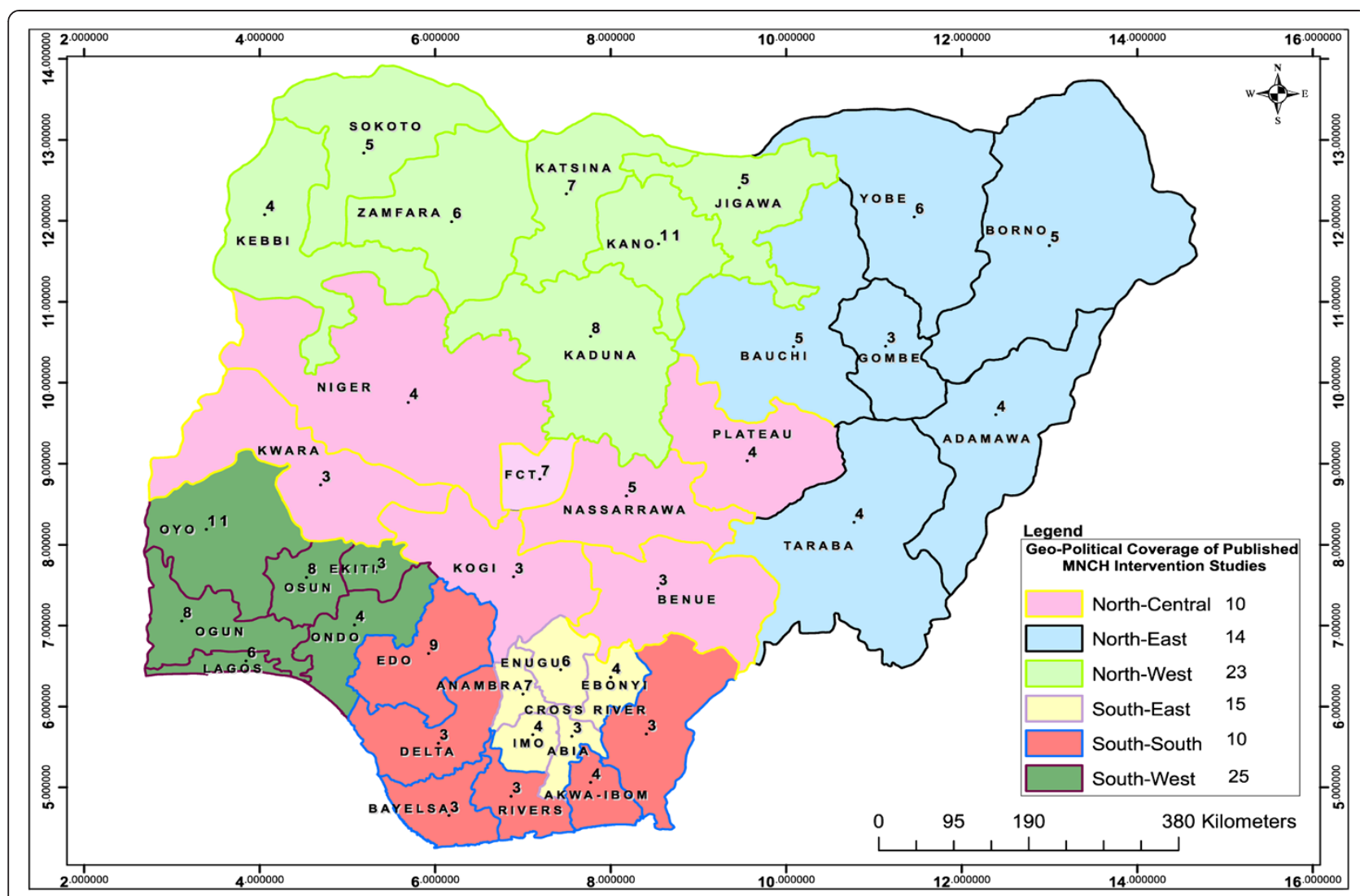

Figure 5 Map of Nigeria illustrating the geographical coverage of published MNCH intervention studies, 1990-2014.




2014) with a marked decrease in the last decade that featured the preponderance of published studies (20042014). Although progress has been recorded since the 1990s in reducing maternal deaths, the number of women who die in pregnancy or from complications associated with childbirth remains significantly high in Nigeria [2]. In 2010, Nigeria is estimated to account for $14 \%$ of maternal deaths worldwide [1]. The maternal mortality trend in Nigeria is inconsistent with the global MMR reduction from $422(358-505)$ in 1980 to 320 (272-388) in 1990, and was 251 (221-289) per 100,000 live births in 2008. The annual rate of decline of the global MMR since 1990 was $1.3 \%(1.0-1.5)$, which is at variance to our estimate for Nigeria (APC $=-3.10 \%, 95 \%$ CI: -5.20 to $-1.00 \%$ ), which was initially lower but an improvement was observed in the 2000s that overlaps with the proliferation of $\mathrm{MNCH}$ interventions. [2].

It is advocated that the concentration and integration of maternal health interventions targeting high risk and vulnerable points during maternity care minimizes morbidity and mortality [111]. Our results show that 21 studies specifically reported interventions targeting pregnancy and childbirth, which are sensitive periods for preventing maternal mortality [112]. In terms of outcome of interventions, our study recorded that maternal health promotion and prevention of complications interventions were targeted by 12 and 21 studies respectively. Furthermore, only 13 studies that reported interventions targeting health system strengthening, which has the potential of wider coverage and sustainability [113].

Nigeria is comprised of complex geographic and demographic characteristics as seen in the significant regional variation in maternal health indicators [16]. The extremely poor north-east region has an estimated MMR of 1,549 deaths per 100,000 live births, more than five times the global average [16]. Our findings showed that only three regional specific and 10 national or multi-regional published studies of $\mathrm{MNCH}$ interventions were recorded in the north-east. The recent terrorist attacks in the north have led to high levels of insecurity thereby creating an unfavorable environment for implementing health intervention programmes. Development partners have in many cases shut down or scaled back operations in the north and public health experts fear that any prolonged insecurity will attenuate the health gains of the last decade [32].

As for child health interventions, only 18 studies specifically targeting under-five children were published during the 24 year-period of observation. The downward trend in the under-five mortality also corresponds with the implementation and publication of most of the $\mathrm{MNCH}$ intervention studies in Nigeria. The regional variation in under-five mortality is accentuated by the consistently higher rates in the northeast and the northwest sub-regions. Our findings showed that these regions did not experience significant reduction compared to the other regions. The findings of the present study show that the included studies targeting under-five children were child health promotion and prevention of childhood diseases were few. The findings of this study also showed that the proliferation of policies and strategies targeting child health were mostly between 20052010. It is known that it requires time and other resources for health policies to be translated into change [114]. Our study has showed that 38 (67.3\%) MNCH interventions were implemented for less than two years. The limited improvement in child health may be partly explained by the late take off, lack of sustenance and disjointed design and non-scaling up of implementation of interventions targeting $\mathrm{MNCH}$.

Currently, policy recommendation favours $\mathrm{MNCH}$ interventions be designed and implemented to address fundamental etiological factors of the mother and child through a comprehensive and continuum of care approach [111]. Efforts to adopt this paradigm so as to improve the health status of mothers and children have been made by the Nigeria Federal Government in collaboration with national and international donors and partners. In 2007, the National Integrated Maternal, Newborn and Child Health (NIMNCH) Strategy was adopted.

Maternal, newborn, and child health outcomes are determined by multiple factors that require multi-pronged interventions operating synergistically to reinforce an overall positive effect [111]. Additionally, it is important to consider $\mathrm{MNCH}$ intervention outcomes and impact in terms of coverage, cost-effectiveness and benefit at the population level. It is reasonable that in a resource constrained setting, interventions should be designed to ensure efficiency and cost-effectiveness. Our results showed that only two studies reported on economic outcome (e.g. cost analysis) of interventions. In addition, it is challenging to demonstrate effectiveness of most interventions since only $35 \%$ of all the published intervention studies had a control or comparison group. This finding emphasizes the role of implementation/operational research and intervention trials/pilots before scale-up especially for the design and implementation of the post-2015 $\mathrm{MNCH}$ intervention projects.

\section{Study limitations}

The indirect measurement of coverage and effectiveness described in this paper is limited to only studies that were published and available on the major search engines employed for this systematic review. Although many interventions have been implemented in Nigeria since 1990, attempts to get an inventory of all implemented interventions were unsuccessful. Therefore, some of these interventions may not have been included 
in this systematic review because they were unavailable for selection or did not meet the inclusion criteria. The barriers to the dissemination and timely application of research findings in the making of decisions about health care are complex and have been little studied [115]. Government and Funding agencies require the evaluation and documentation of implementation results only as programmatic processes [116]. Consequently, these evaluation reports don't get published in academic journals because professional researchers who are motivated to publish did not execute them. This view is supported by our findings that showed $63 \%$ of the published studies having authors affiliated with Nigerian academic/health institutions and foreign donors/ implementing organizations.

\section{Conclusion}

This systematic review has provided important lessons for operational research and the application of epidemiological reasoning to the understanding of $\mathrm{MNCH}$ problems and institution of relevant interventions. Firstly, the prolonged intervention-publication interval may contribute to delayed management awareness, mobilization of resources and response. We also observed a lack of coordination of policies and interventions either as source of evidence for initiating intervention or its evaluation. Furthermore, the scale and duration of many of the interventions was insufficient to have demonstrable impact on maternal and child health outcomes. A number of the $\mathrm{MNCH}$ interventions were implemented as pilots or within the framework of vertical programmes thereby raising concerns for scaling-up for wider coverage, integration into the health system and sustainability.

Despite the limitations associated with the systematic review, the methodology employed ensured that the search strategy covered several sources. The selected studies may not be representative of all implemented interventions but they have revealed interesting findings about the coverage and effectiveness of $\mathrm{MNCH}$ interventions since 1990. Future systematic reviews should focus on grey literature and other data sources in order to improve the sample size and variety of included studies. This systematic review has also shown that more $\mathrm{MNCH}$ intervention research and publications of findings is required to generate local and relevant evidence. Policy and implementation will benefit from this development.

\section{Additional files}

Additional file 1: Completed PRISMA checklist for reporting systematic reviews.

Additional file 2: Table S1. Data extraction tool and included studies' characteristics. Geographical location is classified as NC, NE, NW, SE, SS and SW or State and Local Government Areas (LGA). *NC = North central,
$\mathrm{NE}=$ North east, NW = North west, SE = South east, SS = South south and $\mathrm{SW}=$ South west (regions of the country). ${ }^{* *} \mathrm{CYP}=$ couple years of protection ${ }^{* * *}$ EmOC $=$ Emergency obstetrics care ${ }^{* * * *} Y L S=$ Years of life saved $* * * * *$ MIP $=$ Malaria in $\mathrm{P}^{* * * * * *} \mathrm{CORP}=$ Community oriented resource persons $* * * * * * * N A S G=$ Non Pneumat.

$[18,20,22,27,30,31,49-60,62-71,73-108]$.

\section{Competing interests}

The authors declared that they have no competing interests. There were no sources of funding for this review.

\section{Authors' contributions}

$\mathrm{MK}, \mathrm{BP}$, and HD performed the literature search, screened articles for inclusion and analyzed and interpreted the data, with BP consulting and reviewing MK and HD's work. MK and HD reviewed all full text screened articles and together selected the included studies. MK drafted the manuscript. $\mathrm{HD}$ and BP reviewed, edited and revised the manuscript. NL and HB supervised all the processes. All authors conceived and designed the study and approved the final version.

\section{Acknowledgement}

The views expressed in this paper are those of the authors and do not reflect the views of their organizations or institutions. The authors acknowledge the contributions of the Government of Nigeria, academic institutions and development partners towards promoting MDG 4 and 5 in Nigeria. The Institute of Public Health University of Porto (ISPUP) is appreciated for availing its intellectual and material resources for this systematic review.

\section{Author details}

'Department of Community Medicine, Faculty of Medicine, Kaduna State University, Kaduna, Nigeria. ${ }^{2}$ EPIUnit - Instituto de Saúde Pública da Universidade do Porto (ISPUP), Porto, Portugal. ${ }^{3}$ Integrated Programme and Oversight Branch, Division for Operations, United Nations Office on Drugs and Crime, Abuja, Nigeria. ${ }^{4}$ Department of Clinical Epidemiology, Predictive Medicine and Public Health, University of Porto Medical School, Porto, Portugal.

Received: 13 November 2014 Accepted: 26 March 2015

Published online: 09 April 2015

\section{References}

1. WHO, UNICEF, UNFPA,The World Bank: Trends in maternal mortality: 1990 to 2010. Geneva: World Health Organization; 2012.

2. Kassebaum NJ, Bertozzi-Villa A, Coggeshall MS, Shackelford KA, Steiner C, Heuton KR, et al. Global, regional, and national levels and causes of maternal mortality during 1990-2013: a systematic analysis for the Global Burden of Disease Study 2013. Lancet. 2014;384(9947):980-1004.

3. Abejide OR, Tadese MA, Babajide DE, Torimiro SE, Davies-Adetugbo AA, Makanjuola RO. Non-puerperal induced lactation in a Nigerian community: case reports. Ann Trop Paediatr. 1997;17(2):109-14.

4. UNICEF. Progress for Children:A report card on maternal mortality. New York, USA: United Nations Children Fund; 2008.

5. Doctor HV. Variations in under-five mortality estimates in Nigeria: explanations and implications for program monitoring and evaluation. Matern Child Health J. 2013;17(8):1355-8.

6. Antai D, Moradi T. Urban area disadvantage and under-5 mortality in Nigeria: the effect of rapid urbanization. Environ Health Perspect. 2010;118(6):877-83.

7. Antai D. Regional inequalities in under-5 mortality in Nigeria: a population-based analysis of individual- and community-level determinants. Popul Health Metrics. 2011;9:6

8. Sule SS, Onayade AA. Community-based antenatal and perinatal interventions and newborn survival. Nigerian J of Med. 2006;15(2):108-14

9. Ezeh OK, Agho KE, Dibley MJ, Hall J, Page AN. Determinants of neonatal mortality in Nigeria: evidence from the 2008 demographic and health survey. BMC Public Health. 2014;14:521.

10. Rajaratnam JK, Marcus JR, Flaxman AD, Wang H, Levin-Rector A, Dwyer L, et al. Neonatal, postneonatal, childhood, and under-5 mortality for 187 countries, 1970-2010: a systematic analysis of progress towards Millennium Development Goal 4. Lancet. 2010;375(9730):1988-2008. 
11. Kwast BE. Reduction of maternal and perinatal mortality in rural and peri-urban settings: what works? Eur J Obstet Gynecol Reprod Biol. 1996;69(1):47-53.

12. National Population Commission (NPC) [Nigeria]: Nigeria Demographic and Health Survey 1999. Calverton, Maryland, USA. National Population Commission (NPC) and ORC Macro; 2000.

13. Commission NP. (NPC) [Nigeria] and ORC Macro: Nigeria Demographic and Health Survey, Calverton, Maryland. USA: National Population Commission (NPC) and ORC Macro; 2003. p. 2004.

14. UNICEF. Progress for Children:A report card on maternal mortality. New York, USA: United Nations Children Fund; 2010.

15. National Population Commision (NPC) [Nigeria] and ICF: Nigeria Demographic and Health Survey 2008. Abuja, Nigeria and Calverton, Maryland, USA: National Population Commission and ICF Macro; 2009.

16. Abimbola S, Okoli U, Olubajo O, Abdullahi MJ, Pate MA. The midwives service scheme in Nigeria. PLoS Med. 2012;9(5):e1001211.

17. Shiffman J, Okonofua FE. The state of political priority for safe motherhood in Nigeria. BJOG. 2007;114(2):127-33.

18. Tukur J, Ahonsi B, Ishaku SM, Araoyinbo I, Okereke E, Babatunde AO. Maternal and fetal outcomes after introduction of magnesium sulphate for treatment of preeclampsia and eclampsia in selected secondary facilities: a low-cost intervention. Matern Child Health J. 2013;17(7):1191-8.

19. Garba AM, Bandali S. The Nigeria independent accountability mechanism for maternal, newborn, and child health. Int J Gynaecol Obstet. 2014;127(1):113-6.

20. Okonofua F, Lambo E, Okeibunor J, Agholor K. Health Policy. 2011;99(2:131-8.

21. Findley SE, Doctor HV, Ashir GM, Kana MA, Mani AS, Green C, et al. Reinvigorating Health Systems and Community-Based Services to Improve Maternal Health Outcomes: Case Study From Northern Nigeria. J Prim Care Community Health. 2015;6(2):88-99.

22. Findley SE, Uwemedimo OT, Doctor HV, Green C, Adamu F, Afenyadu GY. Early results of an integrated maternal, newborn, and child health program, Northern Nigeria, 2009 to 2011. BMC Public Health. 2013;13:1034.

23. Federal Minstry of Health [Nigeria]: National Strategic Health Development Plan (NSHDP) 2010-2015. Abuja, Nigeria: Federal Ministry of Health; 2010 http://www.health.gov.ng/doc/NSHDP.pdf. Accessed October 27, 2014.

24. Federal Ministry of Health [Nigeria]: Saving Newborn Lives in Nigeria: Newborn Health in the Context of the Integrated Maternal, Newborn and Child Health Strategy. Abuja, Nigeria: Federal Ministry of Health; 2012. http://www.healthynewbornnetwork.org/sites/default/files/resources/ Nigeria\%20Sit\%20An\%20final\%20lowres_FINAL.pdf. Accessed October 27, 2014.

25. Office of the Senior Special Assistant on MDGs [Nigeria]: Nigeria Millennium Development Goals: Report 2010. Abuja, Nigeria: Government of the Federal Republic of Nigeria; 2010. http://www.undp.org/content/dam/undp/library/ MDG/english/MDG\%20Country\%20Reports/Nigeria/nigeria_2010.pdf. Accessed October 27, 2014

26. Girard AW, Dzingina C, Akogun O, Mason JB, McFarland DA. Public health interventions, barriers, and opportunities for improving maternal nutrition in Northeast Nigeria. Food Nutr Bull. 2012;33(2 Suppl):S51-70.

27. Erim DO, Resch SC, Goldie SJ. Assessing health and economic outcomes of interventions to reduce pregnancy-related mortality in Nigeria. BMC Public Health. 2012;12:786.

28. Mezie-Okoye MM, Adeniji FO, Tobin-West Cl, Babatunde S. Status of emergency obstetric care in a local government area in south-south Nigeria. Afr J Reprod Health. 2012;16(3):171-9.

29. Ushie BA, Fayehun OA, Ugal DB. Trends and patterns of under-5 vaccination in Nigeria, what manner of progress? Child Care Health Dev. 2014;40(2):267-74.

30. Okafor II, Obi SN, Ugwu EO. Impact of free maternal and child healthcare programme on maternal and neonatal healthcare outcome in Enugu state of Nigeria. Niger J Med. 2011;20(4):441-3.

31. Anyaehie U, Nwagha UI, Aniebue PN, Nwagha TU. The effect of free distribution of insecticide-treated nets on asymptomatic Plasmodium parasitemia in pregnant and nursing mothers in a rural Nigerian community. Niger J Clin Pract. 2011;14(1):19-22.

32. Cooke JG T: Maternal Health in Nigeria: with leadership, progress is possible. In. Washington DC, USA: Center for Strategic and International Studies (CSIS); 2013.

33. Ahman E ZJ: Neonatal and perinatal mortality : country, regional and global estimates 2004. In. Geneva, Switzerland: World Health Organization, Department of Making Pregnancy Safer.; 2007.

34. Innvaer SVG, Trommald M, Oxman A. Health policy-makers' perceptions of their use of evidence: a systematic review. J Health Serv Res Policy. 2002;7:239-44.
35. Gasteen M: Systematic Reviews and Evidence-Informed Policy: Overview. Systematic Review Program, DFID Research and Evidence Division; 2010.

36. Sweet M, Moynihan M: Improving Population Health: The Uses of Systematic Reviews. Atlanta, USA: The Centers for Disease Control and Prevention (CDC) and Milbank Memorial Fund; 2007. http://www.milbank.org/uploads/ documents/0712populationhealth/0712ImprovingPopulationHealthFinal.pdf. Accessed October 27, 2014.

37. Moynihan R: Evaluating Health Services: A Reporter Covers the Science of Research Synthesis Atlanta, USA: Milbank Memorial Fund; 2004. http://www.milbank.org/ uploads/documents/2004Moynihan/Moynihan.pdf. Accessed October 27, 2014

38. Oliver K, Innvar S, Lorenc T, Woodman J, Thomas J. A systematic review of barriers to and facilitators of the use of evidence by policymakers. BMC Health Services Research. 2014;14:2.

39. Badger DJN, Williams P, Woodward M. Should All literature reviews be systematic?". Evaluation and Research in Education Education. 2000;14(3\&4):220-3.

40. Armstrong R WE, Jackson N, Oliver S, Popay J, Shepherd J, Petticrew M, Anderson L, Bai I ie R BG, Hawe P, Kristjansson E, Naccarel la L, Norris S,

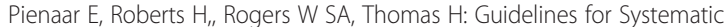
reviews of health promotion and public health interventions Version 2. Melbourne, Australia: Melbourne University, Australia; 2007.

41. Federal Office of Statistics [Nigeria] and IRD/Macro International Inc: Nigeria Demographic and Health Survey 1990. Lagos, Nigeria and Columbia. Maryland, USA: Federal Office of Statistics and IRD/Macro International Inc.; 1992.

42. National Population Commission (NPC) [Nigeria] and ICF International. Nigeria Demographic and Health Survey 2013. Abuja, Nigeria and Rockville, Maryland, USA: NPC and ICF International; 2014.

43. Glasziou P, Vandenbroucke JP, Chalmers I. Assessing the quality of research. BMJ. 2004:328(7430):39-41.

44. The Partnsership for Maternal Newborn and Child Health: A Global Review of the Key Interventions Related to Reproductive, Maternal, Newborn and Child Health (RMNCH). Geneva, Switzerland: World Health Organization; 2011.

45. ESRI. ArcGIS Desktop. Release 10. Environmental Systems Research Institute: Redlands, California, USA; 2011.

46. Kim HJFM, Feuer EJ, Midthune DN. Permutation tests for joinpoint regression with applications to cancer rates. Stat Med. 2000;19:335-51.

47. Joinpoint Regression Program, Version 4.1.1: Statistical Methodology and Applications Branch, Surveillance Research Program, National Cancer Institute; 2014

48. Federal Ministry of Health [Nigeria]: An Annonated National Bibliography on Digitilized Health Policies and Guidelines in Nigeria. Abuja, Nigeria: Federal Ministry of Health; 2012.

49. Amoran OE. Impact of health education intervention on malaria prevention practices among nursing mothers in rural communities in Nigeria. Niger Med J. 2013;54(2):115-22

50. Prata N, Ejembi C, Fraser A, Shittu O, Minkler M. Community mobilization to reduce postpartum hemorrhage in home births in northern Nigeria. Social science \& medicine. 2012;74(8):1288-96.

51. Ajayi IO, Falade CO, Bamgboye EA, Oduola AM, Kale OO. Assessment of a treatment guideline to improve home management of malaria in children in rural south-west Nigeria. Malar J. 2008;7:24.

52. Abdul-Hadi RA, Abass MM, Aiyenigba BO, Oseni LO, Odafe S, Chabikuli ON, et al. The effectiveness of community based distribution of injectable contraceptives using community health extension workers in Gombe State, Northern Nigeria. Afr J Reprod Health. 2013;17(2):80-8.

53. Gwarzo NS, Aliyu GG, Gasasira A, Aliyu MH, Zubair M, Mandawari SU, et al. Breaking community barriers to polio vaccination in Northern Nigeria: the impact of a grass roots mobilization campaign (Majigi). Pathogens and global health. 2012;106(3):166-71.

54. Ogu R, Okonofua F, Hammed A, Okpokunu E, Mairiga A, Bako A, et al. Outcome of an intervention to improve the quality of private sector provision of postabortion care in northern Nigeria. International journal of gynaecology and obstetrics: the official organ of the International Federation of Gynaecology and Obstetrics. 2012;118 Suppl 2:S121-126.

55. Amoran OE, Fatugase KO, Fatugase OM, Alausa KO. Impact of health education intervention on insecticide treated nets uptake among nursing mothers in rural communities in Nigeria. BMC research notes. 2012;5:444.

56. Fatungase $\mathrm{KO}$, Amoran $\mathrm{OE}$, Alausa $\mathrm{KO}$. The effect of health education intervention on the home management of malaria among the caregivers of 
children aged under 5 years in Ogun State. Nigeria European journal of medical research. 2012;17:11.

57. Qureshi AM, Oche OM, Sadiq UA, Kabiru S. Using community volunteers to promote exclusive breastfeeding in Sokoto State. Nigeria The Pan African medical journal. 2011;10:8.

58. Adinma ED, Nwakoby BA, Adinma BD. Integrating maternal health services into a health insurance scheme: effect on healthcare delivery. Nigerian quarterly journal of hospital medicine. 2010;20(2):86-93.

59. Aja GN, Umahi EN, Allen-Alebiosu OI. Developing culturally-oriented strategies for communicating women's health issues: a church-based intervention. Educ Health. 2011;24(1):398.

60. Miller S, Ojengbede O, Turan JM, Morhason-Bello IO, Martin HB, Nsima D. A comparative study of the non-pneumatic anti-shock garment for the treatment of obstetric hemorrhage in Nigeria. Int J Gynecol Obstetrics. 2009;107(2):121-5

61. Adinma ED, Brian DAJl, Obionu CC, Asuzu MC. Effect of governmentcommunity healthcare co-financing on maternal and child healthcare in Nigeria. West Afr J Med. 2011;30(1):35-41.

62. Ojengbede OA, Morhason-Bello IO, Galadanci H, Meyer C, Nsima D, Camlin $\mathrm{C}$, et al. Assessing the role of the non-pneumatic anti-shock garment in reducing mortality from postpartum hemorrhage in Nigeria. Gynecol Obstet Investig. 2011;71(1):66-72.

63. Thompson A, Castle E, Lubeck P, Makarfi PS. Experience implementing OpenMRS to support maternal and reproductive health in Northern Nigeria. Studies in health technology and informatics. 2010;160(Pt 1):332-6.

64. Chabikuli NO, Awi DD, Chukwujekwu O, Abubakar Z, Gwarzo U, Ibrahim M, et al. The use of routine monitoring and evaluation systems to assess a referral model of family planning and HIV service integration in Nigeria. AIDS. 2009;23 Suppl 1:S97-S103.

65. Okeke TA. Improving malaria recognition, treatment and referral practices by training caretakers in rural Nigeria. J Biosoc Sci. 2010;42(3):325-39.

66. Okeke TA, Uzochukwu BS. Improving childhood malaria treatment and referral practices by training patent medicine vendors in rural south-east Nigeria. Malar J. 2009;8:260

67. Hunyinbo KI, Fawole AO, Sotiloye OS, Otolorin EO. Evaluation of criteriabased clinical audit in improving quality of obstetric care in a developing country hospital. Afr J Reprod Health. 2008;12(3):59-70.

68. Chirdan OO, Zoakah Al, Ejembi CL. Impact of health education on home treatment and prevention of malaria in Jengre, North Central Nigeria. Annals of African medicine. 2008;7(3):112-9.

69. Okechukwu AA, Abdulrahaman IE. The impact of prevention of mother to child transmission of HIV programme in the federal capital territory, Abuja. Nigerian journal of medicine : journal of the National Association of Resident Doctors of Nigeria. 2008;17(2):191-7.

70. Mens PF, Scheelbeek PF, Al Atabbi H, Enato EF. Peer education: the effects on knowledge of pregnancy related malaria and preventive practices in women of reproductive age in Edo State. Nigeria BMC public health. 2011;11:610

71. Odusanya OO, Alufohai JE, Meurice FP, Clemens R, Ahonkhai VI. Short term evaluation of a rural immunization program in Nigeria. J Natl Med Assoc. 2003:95(2):175-9.

72. Oche OM, Onankpa OB. Using women advocacy groups to enhance knowledge and home management of febrile convulsion amongst mothers in a rural community of Sokoto State. Nigeria The Pan African medical journal. 2013;14:49

73. Ashir GM, Doctor HV, Afenyadu GY. Performance based financing and uptake of maternal and child health services in yobe sate, northern Nigeria. Global journal of health science. 2013:5(3):34-41.

74. Findley SE, Uwemedimo OT, Doctor HV, Green C, Adamu F, Afenyadu GY. Comparison of high- versus low-intensity community health worker intervention to promote newborn and child health in Northern Nigeria. International journal of women's health. 2013;5:717-28.

75. Okeibunor JC, Orji BC, Brieger W, Ishola G, Otolorin E, Rawlins B, et al. Preventing malaria in pregnancy through community-directed interventions: evidence from Akwa Ibom State. Nigeria Malaria journal. 2011;10:227.

76. Ajayi IO, Falade CO, Kale OO. An assessment of accuracy of mothers' presumptive diagnosis of fever at home in southwest Nigeria: evidence for switch to parasite-based diagnostic test. East African journal of public health. 2009;6(3):229-34.

77. Speizer IS, Corroon M, Calhoun L, Lance P, Montana L, Nanda P, et al. Demand generation activities and modern contraceptive use in urban areas of four countries: a longitudinal evaluation. Global Health, Science and Practice. 2014;2(4):410-26.

78. McNabb M, Chukwu E, Ojo O, Shekhar N, Salami H, Jega F. Assessment of the quality of antenatal care services provided by health workers using a mobile phone decicion support application in northern Nigeria: a pre/post-intervention study. Pathfinder International: Watertown, Massachusetts; 2014.

79. Ezugwu EC, Agu PU, Nwoke MO, Ezugwu FO. Reducing maternal deaths in a low resource setting in Nigeria. Niger J Clin Pract. 2014;17(1):62-6.

80. Sutherland T, Downing J, Miller S, Bishai DM, Butrick E, Fathalla MMF, MouradYoussif M, Ojengbede O, Nsima D, Kahn JG: Use of the Non-Pneumatic Anti-Shock Garment (NASG) for Life-Threatening Obstetric Hemorrhage: A Cost-Effectiveness Analysis in Egypt and Nigeria. PLoS One 2013, 8(4).

81. Okonofua FE, Ogu RN, Fabamwo AO, Ujah IO, Chama CM, Archibong El, et al. Training health workers for magnesium sulfate use reduces case fatality from eclampsia: results from a multicenter trial. Acta Obstet Gynecol Scand. 2013;92(6):716-20.

82. Kalu CA, Umeora OU, Sunday-Adeoye I. Experiences with provision of postabortion care in a university teaching hospital in south-east Nigeria: a five year review. Afr J Reprod Health. 2012;16(1):105-12.

83. Igwegbe AO, Eleje GU, Ugboaja JO, Ofiaeli RO. Improving maternal mortality at a university teaching hospital in Nnewi, Nigeria. International journal of gynaecology and obstetrics: the official organ of the International Federation of Gynaecology and Obstetrics. 2012;116(3):197-200.

84. Pathfinder I. The Maternal Health Care Improvement Initiative: Nigeria. Pathfinder International: Abuja, Nigeria; 2011.

85. Okanlawon FA, Asuzu MC. Effect of peer education intervention on secondary school adolescents' reproductive health knowledge in Saki, Nigeria. Afr J Med Med Sci. 2011;40(4):353-60.

86. Joseph O, Biodun O, Michael E. Pregnancy outcome among HIV positive women receiving antenatal HAART versus untreated maternal HIV infection. Journal of the College of Physicians and Surgeons Pakistan. 2011;21(6):356-9.

87. Ikechebelu Jl, Ugboaja JO, Kalu SO, Ugochukwu EF. The outcome of prevention of mother to child transmission (PMTCT) of HIV infection programme in Nnewi, southeast Nigeria. Nigerian Journal of Medicine. 2011:20(4):421-5.

88. Hotchkiss DR, Godha D, Do M. Effect of an expansion in private sector provision of contraceptive supplies on horizontal inequity in modern contraceptive use: evidence from Africa and Asia. Int J Equity Health. 2011;10:33.

89. Galadanci H, Kunzel W, Shittu O, Zinser R, Gruhl M, Adams S. Obstetric quality assurance to reduce maternal and fetal mortality in Kano and Kaduna State hospitals in Nigeria. Int J Gynaecol Obstet. 2011;114(1):23-8.

90. Gage AJ. End-of project health facility survey 2009: final report. Community participation for action in the social sector (COMPASS) project [Nigeria]. Chapel Hill, North Carolina: MEASURE Evaluation, Carolina Population Center, North Carolina, University of North Carolina at Chapel Hill; 2011.

91. Fayemi M, Momoh G, Oduola O, Delano G, Ladipo O, Adebola O. Community based distribution agents' approach to provision of family planning information and services in five Nigerian States: A mirage or a reality? African J of Primary Health Care and Family Med. 2011;3(1):9.

92. Adeleye OA, Aldoory L, Parakoyi DB. Using local culture and gender roles to improve male involvement in maternal health in southern Nigeria. J Health Commun. 2011;16(10):1122-35.

93. Ukwaja KN, Aina OB, Talabi AA. Outcome of presumptive versus rapid diagnostic tests-based management of childhood malaria - pneumonia overlap in urban Nigeria: a pilot quasi-experimental study. Ethiop J Health Sci. 2010;20(3):179-83.

94. Kirwan P, Asaolu SO, Molloy SF, Abiona TC, Jackson AL, Holland CV. Patterns of soil-transmitted helminth infection and impact of four-monthly albendazole treatments in preschool children from semi-urban communities in Nigeria: a double-blind placebo-controlled randomised trial. BMC Infect Dis. 2009;9:20.

95. Asekun-Olarinmoye EO, Amusan OA. The impact of health education on attitudes towards female genital mutilation (FGM) in a rural Nigerian community. European Journal of Contraception and Reproductive Health Care. 2008;13(3):289-97.

96. Asa OO, Onayade AA, Fatusi AO, ljadunola KT, Abiona TC. Efficacy of intermittent preventive treatment of malaria with sulphadoxinepyrimethamine in preventing anaemia in pregnancy among Nigerian women. Matern Child Health J. 2008;12(6):692-8. 
97. Sule SS, Onayade AA, Abiona TC, Fatusi AO, Ojofeitimi EO, Esimai OA, et al Impact of nutritional education on nutritional status of under-five children in two rural communities of south-west Nigeria. Niger Postgrad Med J. 2009;16(2):115-25.

98. Ajayi IO, Browne EN, Bateganya F, Yar D, Happi C, Falade CO, et al Effectiveness of artemisinin-based combination therapy used in the context of home management of malaria: a report from three study sites in sub-Saharan Africa. Malar J. 2008;7:190.

99. Mba Cl, Obi SN, Ozumba BC. The impact of health education on reproductive health knowledge among adolescents in a rural Nigerian community. J Obstet Gynaecol. 2007;27(5):513-7.

100. Adesina FA, Olatubara O, Eniola F: The impact of innovative intervention on emergency obstetric care in Osun State. Ede, Nigeria: Center for Research, Evaluation Resources, and Development, 1999.p115-125.

101. Mojidi KL: Increasing male participation: lessons from Mali, Kenya and Nigeria. Grassroots to Global Networks. ACCESS: Lessons Learned Presentation Paper; 1998. http://www.popline.org/node/523262 Accessed16 Feb 2015

102. Davies-Adetugbo AA, Adebawa HA. The Ife South Breastfeeding Project: training community health extension workers to promote and manage breastfeeding in rural communities. Bull World Health Organ. 1997;75(4):323-32

103. Chiwuzie J, Okojie O, Okolocha C, Omorogbe S, Oronsaye A, Akpala W, et al. Emergency loan funds to improve access to obstetric care in Ekpoma, Nigeria. Int J Gynecol Obstet. 1997;59:S231-6.

104. Brieger WR, Ogunlade PB: Process evaluation of the Community Partners for Health Program of BASICS/Nigeria, September - December 1997. In.: Arlington, Virginia: Partnership for Child Health Care, Basic Support for Institutionalizing Child Survival [BASICS], 1997.

105. Ministry of Health [Nigeria], Center for Populationa and Family Health, Columbia University: Report of Community-based distribution (CBD) of low cost family planning and maternal and child health services in rural Nigeria (expansion). New York, Unites States of America: Population Council;1993.

106. Gummi FB, Hassan M, Shehu D, Audu L. Community education to encourage use of emergency obstetric services, Kebbi State, Nigeria. Int J Gynaecol Obstet. 1997;59 Suppl 2:S191-200.

107. Molta NB, Daniel HI, Watila IM, Oguche SO, Otu TI, Ameh JO, et al. Efficacies of chloroquine, pyrimethamine/sulphadoxine and pyrimethamine/ sulphalene against $P$. falciparum in northeastern Nigeria. The Journal of tropical medicine and hygiene. 1992;95(4):253-9.

108. Galadanci HS, Idris SA, Sadauki HM, Yakasai IA: Programs and policies for reducing maternal mortality in Kano State, Nigeria: a review. African journal of reproductive health 2010, 14(3 Spec No):31-36.

109. McArthur J: Own the Goals: What the Millennium Development Goals Have Accomplished. Foreign Affairs 2013.

110. Okon EO. Five decades of development Aid to Nigeria: the impact on human development. Journal of Economics and Sustainable Development. 2012:3(1):32-43

111. Lassi ZS, Kumar R, Mansoor T, Salam RA, Das JK, Bhutta ZA. Essential interventions: implementation strategies and proposed packages of care. Reproductive Health. 2014;11 Suppl 1:S5

112. Ganatra BR, Coyaji KJ, Rao VN. Too far, too little, too late: a community-based case-control study of maternal mortality in rural west Maharashtra, India. Bull World Health Organ. 1998;76(6):591-8.

113. Duran A, Kutzin J, Menabde N. Universal coverage challenges require health system approaches; the case of India. Health policy. 2014;114(2-3):269-77.

114. Grimshaw JM, Eccles MP, Lavis JN, Hill SJ, Squires JE. Knowledge translation of research findings. Implement Sci. 2012;7:50.

115. Haynes B, Haines A. Barriers and bridges to evidence based clinical practice. BMJ. 1998;317(7153):273-6

116. Mouton C. The history of programme evaluation in South Africa. MPhil Dissertation, University of Stellenbosch; 2010. 218 pp.

\section{Submit your next manuscript to BioMed Central and take full advantage of:}

- Convenient online submission

- Thorough peer review

- No space constraints or color figure charges

- Immediate publication on acceptance

- Inclusion in PubMed, CAS, Scopus and Google Scholar

- Research which is freely available for redistribution

Submit your manuscript at www.biomedcentral.com/submit 